\title{
Laser Interstitial Thermal Therapy
}

National Cancer Institute

\section{Source}

National Cancer Institute. Laser Interstitial Thermal Therapy. NCI Thesaurus. Code C68680.

A thermal ablation therapy in which neoplasms are heated with prolonged and moderate temperature elevations. It results in coagulative necrosis in the heated tissue. 